International Journal of Biology, Pharmacy and Allied Sciences (IJBPAS)

'A Bridge Betuen Caboratory and QRando'

WWW.ibpas.com

\title{
ASSESSMENT OF INSTRUMENT SEPARATION DONE BY THE DENTAL STUDENTS
}

\section{MEERA THEENATHAYALAN ${ }^{1}$, MAHALAKSHMI ${ }^{2 *}$ AND DEEPAK.S $\mathrm{S}^{3}$}

1: Saveetha Dental College and Hospitals, Saveetha Institute of Medical and Technical Sciences, Saveetha University, Chennai,India

2: Senior Lecturer, Department of Conservative Dentistry and Endodontics, Saveetha Dental College and Hospitals, Saveetha Institute of Medical and Technical Sciences, Saveetha University, Chennai, India

3: Senior Lecturer, Department of Conservative Dentistry and Endodontics, Saveetha Dental College, Saveetha Institute Of Medical and Technical Sciences Saveetha University, Chennai, India

*Corresponding Author: E Mail: Dr. Mahalakshmi: mahalakshmii.sde@saveetha.com Received 19 ${ }^{\text {th }}$ March 2021; Revised 20 ${ }^{\text {th }}$ April. 2021; Accepted 19 ${ }^{\text {th }}$ May 2021; Available online $1^{\text {st }}$ Aug. 2021 https://doi.org/10.31032/IJBPAS/2021/10.8.1009

\begin{abstract}
Instrument separation or breakage usually is caused by improper use or overuse of the instruments, as well as by excessive force applied to the instruments in curved or calcified canals during instrumentation. The aim of the study was to evaluate the number of instrument separation done by the dental students. Data collection was done from the patients case records and entered in the excel sheet. Parameters assessed were age, gender, teeth no. and instrumentation separation. The data collection was tabulated in excel and data analysis was done using SPSS software. The association between study variables was calculated using the chi-square test. The result showed 65 cases with instrument separation. The case report for the year showed $23.4 \%$ of cases with instrument separation. The frequency was seen to be 27.2\%. The chi square test showed negative correlation between gender and teeth no. ( $\mathrm{P}$ value $>0.05$ ). This procedural mishap can be effectively minimized if all basic principles and rules regarding access cavity preparation and root canal mechanical instrumentation are wellprovided.
\end{abstract}

Keywords: Instrument separation, Nickel-titanium rotary Files, Stainless steel hand files, Root canal treatment 


\section{INTRODUCTION}

Root canal treatment (RCT) is an important element of comprehensive dental health care; previous studies have reported success rate $>90 \%$ for $\mathrm{RCT}$ under controlled conditions. However, this high success rate has been reported to decrease to $40-65 \%$ in cases where $\mathrm{RCT}$ is performed by a general practitioner. This decrease can be attributed to the inadequate educational programs and lack of self confidence in performing root canal procedures. Therefore, it is important to improve undergraduate programs, where it is possible to recognize the reason that affects the success of dental treatment [1, 2].

In root canal treatment, several factors determine the technical quality of the root canal steps, for example while obturating, the distance between the end of the root canal obturation materials and the root apex, dentistry, presence of voids and taper. All these features can be appreciated radiographically. Underlying and overfilling of a root canal obturation will also compromise the success rate of RCT. In addition, other iatrogenic errors such as instrument fractures, ledge formation, and apical perforation can cause failures of non surgical RCT. Several studies have reported the adequacy of RCT performed by undergraduate students as varying between $33 \%$ and $70 \%$.
Assessment of treatment quality and frequency of procedural errors will help improve educational programs and enhance health services. An increasing number of new nickel-titanium (NiTi) rotary file systems are currently available.

Recently developed Niti files possess unique design properties in terms of cross sectional shape, taper, surface treatment (electro - polishing), the number and angle of flutes and so forth. In 1988, which et al, introduced new materials for the manufacturing of endodontic instruments: nickel titanium NiTi instruments exhibit more elastic flexibility in bending and torsion, as well as superior resistance to corrosion compared with stainless - steel files manufactured by the same process. A number of studies have shown that these NiTi rotary systems are able to prepare root canals are excellent taper, less canal transportation, greater conservation of tooth structure, and at a much faster rate than hand files [3-4].

However, despite the evident advantages of the new techniques, NiTi rotary instruments may experience failures by fatigue or torsion. Different studies have suggested that cyclic fatigue (flexural and torsional) caused by repeated tensile compressive stress plays an important role in the fracture of instruments $[5,6]$. 
Previously our team had conducted numerous clinical trials and lab animal studies and in vitro students over the past 5 years [7-21]. Now we are focussing on epidemiological surveys. The idea for this survey stemmed from the current interest in our community.

\section{MATERIALS AND METHODS}

Ethical permission and approval for the project was obtained from the institutional review board of Saveetha Institute Of Medical And Technical Sciences, Chennai, India from June 2019 to March 2020 be covered by following ethical approval number

\section{SDC/SIHEC/2020/DIASDATA/0619-}

0320. A dental record of 65 patients were investigated who reported with instrument separation or file breakage. Data was evaluated and entered in the excel sheet. The male and female distribution among the study population was evaluated. The collection of data was divided on 4 parameters, the age of the patient, the gender of the patient, teeth number and instrument separation. After grouping the parameters, data copied to the software and statistical analysis was carried out. Statistical analysis was done using IBM SPSS software. The significance level was at 0.005 . Descriptive analysis and chisquare tests were done. Graphs were tabulated. Inclusion Criteria: Patients of age group 0-30 years were included, and both male and females were included. Exclusion Criteria: Other than instrument separation, other endodontic mishap like perforation, endo surgery were excluded.

\section{RESULTS \& DISCUSSION}

The most common affected age group was found to be 30-39 years, followed by 40-49 years. Percentage of females and males among the population were $60 \%$ and $40 \%$ respectively. The 1 st quadrant and 2nd quadrant had the most instrument breakage. The upper posteriors showed the most number of separation of instrument. There was a significant difference shown in the teeth number and age of the affected patients. Association between age and gender with instrument separation showed p - value to be 2.08, which showed a negative correlation between two parameters (Graph 1). Association between age and teeth no. in patients with instrument separation showed $\mathrm{p}$ - value to be 0.00 , which showed a positive correlation between two parameters (Graph 2). Association between gender and teeth no. in patients with instrument separation showed $\mathrm{p}$ value to be 1.005 , which showed a negative correlation between two parameters (Graph 3).

This study was conducted to evaluate the number of instrument separation done by the undergraduate and postgraduate students of saveetha dental 
college from the year 2019-20. Evaluation was done by recording the present data. Around that $23.4 \%$ showed instrument retrieval and caused a procedure error of $68.5 \%$ throughout the success rate of root canal treatment. These differences of the study from previous studies and present study may be due to differences in the evaluated criteria, materials, educational system, methodology and sample size between the present and previous studies. Instrument separation or breakage usually is caused by improper use or overuse of the instruments, as well as by excessive force applied to the instruments in curved or calcified canals during instrumentation. Accordingly, instrument separation is not the direct cause of endodontic therapy failure; rather, the separated instrument impedes the mechanical instrumentation of the infected root canal apical to the instrument, and that is the primary cause of treatment failure.

The stainless steel hand files are usually used, at least in our Graduate Program, in a step-back motion, which means that the preparation technique is different in relation to the NiTi rotary instruments, which are typically used in a crown-down motion. Moreover, the use of an electric low torque motor might reduce the possibility of cyclic flexural fatigue or torsional failure of a rotary instrument [22]. On the contrary, any fracture of stainless steel hand instruments occurs under totally different conditions (excessive manual apical pressure or rotation of the instrument) in relation to a fracture of $\mathrm{NiTi}$ rotary instruments [23]. In this study, the instrument separation alone by the undergraduate and postgraduate done in around $23.4 \%$ of causes reporting for instruments separating. We consider that too many different parameters are involved in the fracture of both stainless steel hand files and NiTi rotary files. The heterogeneity of these parameters makes the above comparison to be quite difficult without any significant clinical relevance. It is possible for anyone to estimate that the percentage of stainless steel hand instrument fracture in our clinic is quite high. On the other hand, one might consider that the respective percentage of $\mathrm{NiTi}$ rotary instruments is quite low in relation to the number of cases treated. Under the working conditions of our graduate clinic, we suggest that both the percentages were relatively low.

A variety of complications may be associated with removal of separated instruments [24-25]. Ledge formation is common and usually prevents preparing and filling the root canal system to the desired length [26]. Ledges are also potential areas of stress concentration that may contribute to vertical root fracture [27]. With the aid of magnification, ledges 
can be reduced or even removed by inserting a rotary file with greater taper or a precurved hand file and applying an axial filing movement with 1- to 2-mm amplitude. If the ledge is apically located and a straight-line access exists, a flexible rotary instrument can be inserted, the ledge bypassed, and the instrument used to smooth the ledge by using an outward brushing movement.

Nevertheless, great care should be exercised when attempting to deal with a ledge that is close to the root canal terminus because it may lead to excessive reduction of the remaining wall thickness and root perforation. Instruments used for removal may themselves separate and complicate treatment further. This is more likely to occur when the fragment is removed by braided Hedstrom files or Kfiles [23] or ultrasonics [28]. Such a complication can be avoided; for example, ultrasonic tips should be used without irrigation to maintain constant vision, and more importantly, they should be activated at a low power setting. This reduces heat generated within the root canal and, therefore, lowers the risk of secondary separation of the fragment itself or the ultrasonic tip. In addition, it minimizes the risk of heat generated on the external root surface [36] and its damaging effect on periodontal tissues [27]. In this respect, incorporating an air flow function into the ultrasonic handpiece is advantageous [29]. Nevertheless, activating ultrasonic tips for prolonged periods can cause severe periodontal tissue damage and may result in tooth loss [6]. Preparation of straight-line access to visualize the fragment is an essential step when attempting fragment retrieval. Most methods and techniques require additional preparation of the root canal, depending on the technique used. When ultrasonics is used, it is recommended to prepare the staging platform by using modified Gates Glidden burs. Consequently, this considerable loss of dentin may be of concern. The deeper the separated instrument within the root canal, the greater the amount of prepared root substrate, and the weaker the root [30, 31].

Another consequence of excessive root canal preparation is root perforation (stripping), especially when preparing the staging platform. Even when a clinician tries to bypass a fragment or a ledge by using hand files, root perforation is still possible, especially in curved root canals or when the roots are thin. Therefore, great care and caution should be exercised, particularly on root canal walls near the furcation area. Extrusion of the fragment apically or even beyond the root apex is a complication that usually results from excessive pressure applied on instruments used for removal or from the vibration of ultrasonic instruments, 
particularly if applied to its end surface rather than around its periphery. Once again, a careful approach can reduce the risk of such an undesirable event. When conservative management of a separated instrument fails and clinical and/or radiographic follow-up indicates presence of disease, surgical intervention may be warranted if the tooth is to be retained. In addition, because of the evidence of adverse impact of periapical lesions on root canal treatment outcome, a surgical approach can be considered as the optimum management choice if the fragment is inaccessible and a periapical lesion is present at the time of instrument separation. However, some cases are not amenable to surgery because of the location of the surgical area and vital anatomic structures. Surgical management includes apical surgery, intentional replantation, root amputation, or hemisection. These different options and approaches should be discussed with the patient, and a suitable treatment plan devised. When root-end resection is performed, a separated fragment located in the apical root section is removed as a part of the procedure. Otherwise, if the fragment is located in the middle or coronal part of the root canal, the root-end cavity can be prepared and sealed with a root-end filling without fragment removal. In both instances, elimination of bacteria and infected tissue as well as providing an excellent coronal and apical seal of the root canal system are essential. Several materials including zinc oxide-eugenol cement, intermediate restorative material, glass ionomer cements, amalgam, and mineral trioxide aggregate cement have been used as root-end filling materials. Although there are many laboratory studies comparing the properties of different rootend filling materials, little information from well-designed, long-term follow-up clinical trials is available. It can be said that important innovations such as surgical ultrasonic tips, dental operating microscopes, and biocompatible root end filling materials have contributed to a better outcome for endodontic surgery [32, 33].

The Limitation of the study was found to be small sample size. In the future, we anticipate reducing further the fracture frequency of root canal instruments used by dental students. 


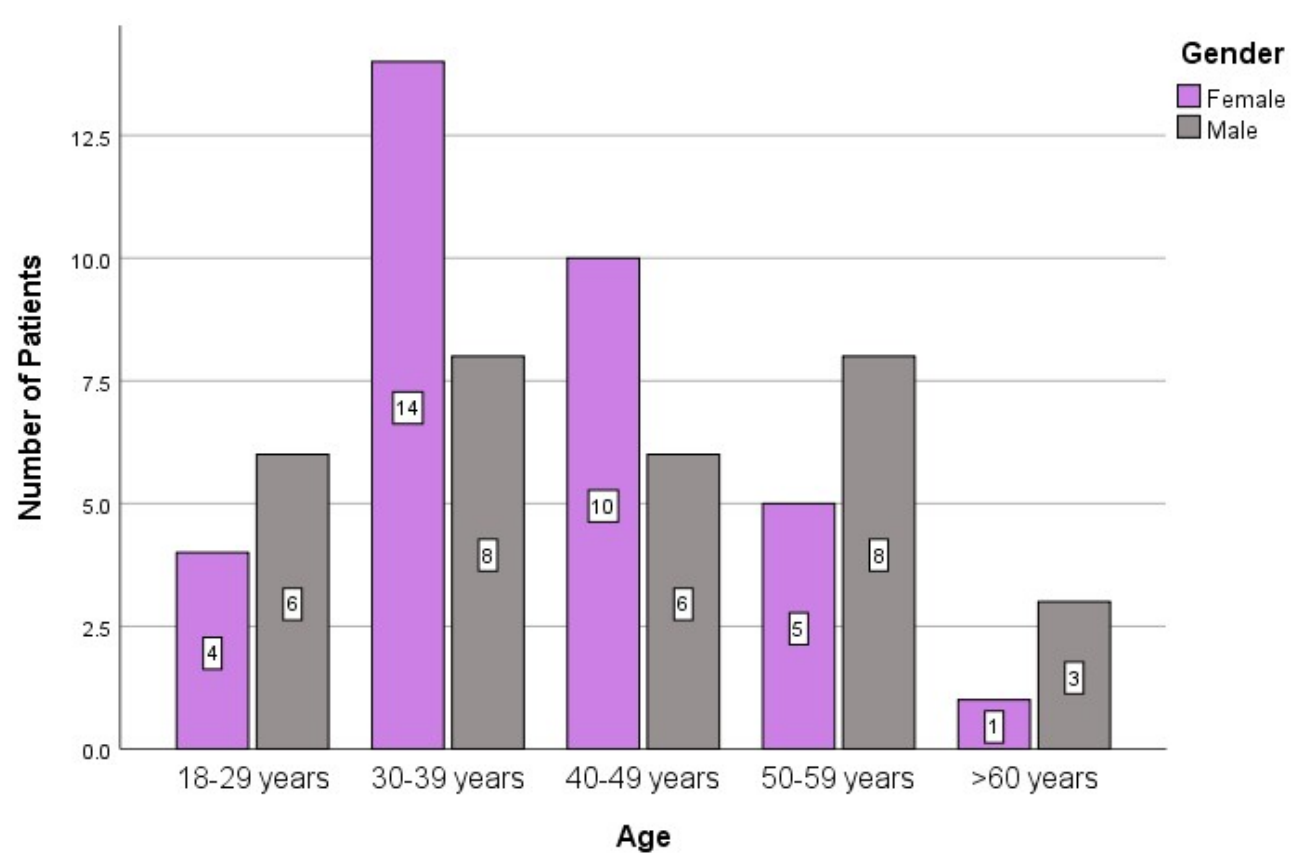

Figure 1: Bar graph showing the association between the age of the patient and gender of the patients who reported with instrument separation. The $X$ axis denotes the age of the patient and gender of the patient. $Y$ axis represents the number of the patient reported with instrument separation. The purple colour denotes the no. of female patients reported with instrument separation and grey colour denotes the no. of male patients reported with instrument separation. It was found that in the age group 30-39 years, the no. of male and female presented with instrument breakage were maximum than other age groups. Chi square statistical test was done and the association was found to be not significant with $p$ value 1.005 (P value - >0.005, statistically not significant).

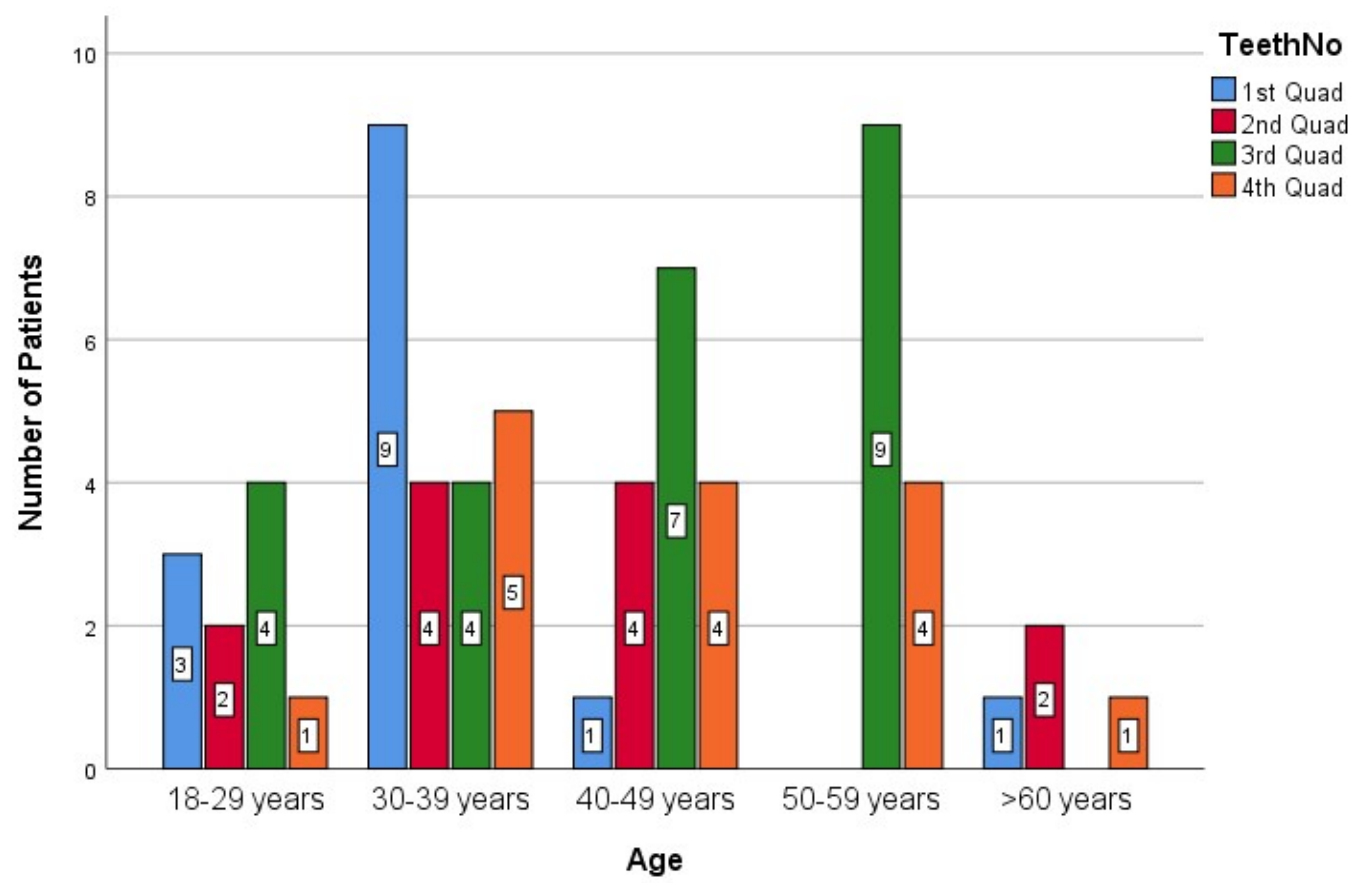

Figure 2: Bar graph showing the association between the age of the patient and teeth no. of the patients who reported with instrument separation. The $X$ axis denotes the age of the patient and teeth no. $Y$ axis represents the number of the patient reported with instrument separation. The blue colour denotes the 1st quadrant with instrument separation, red colour denotes the 2 nd quadrant with instrument separation, green colour denotes the 3rd quadrant with instrument separation and orange colour denotes the 4th quadrant with instrument separation. It was found that the 1st quadrant and 3rd quadrant instrument separation or breakage was more common and the maximum separation or breakage was seen among the 30-39 years age group and 50-59 years age group. Chi square statistical

test was done and the association was found to be significant with $p$ value .000 (P value $-<0.005$, statistically significant). 


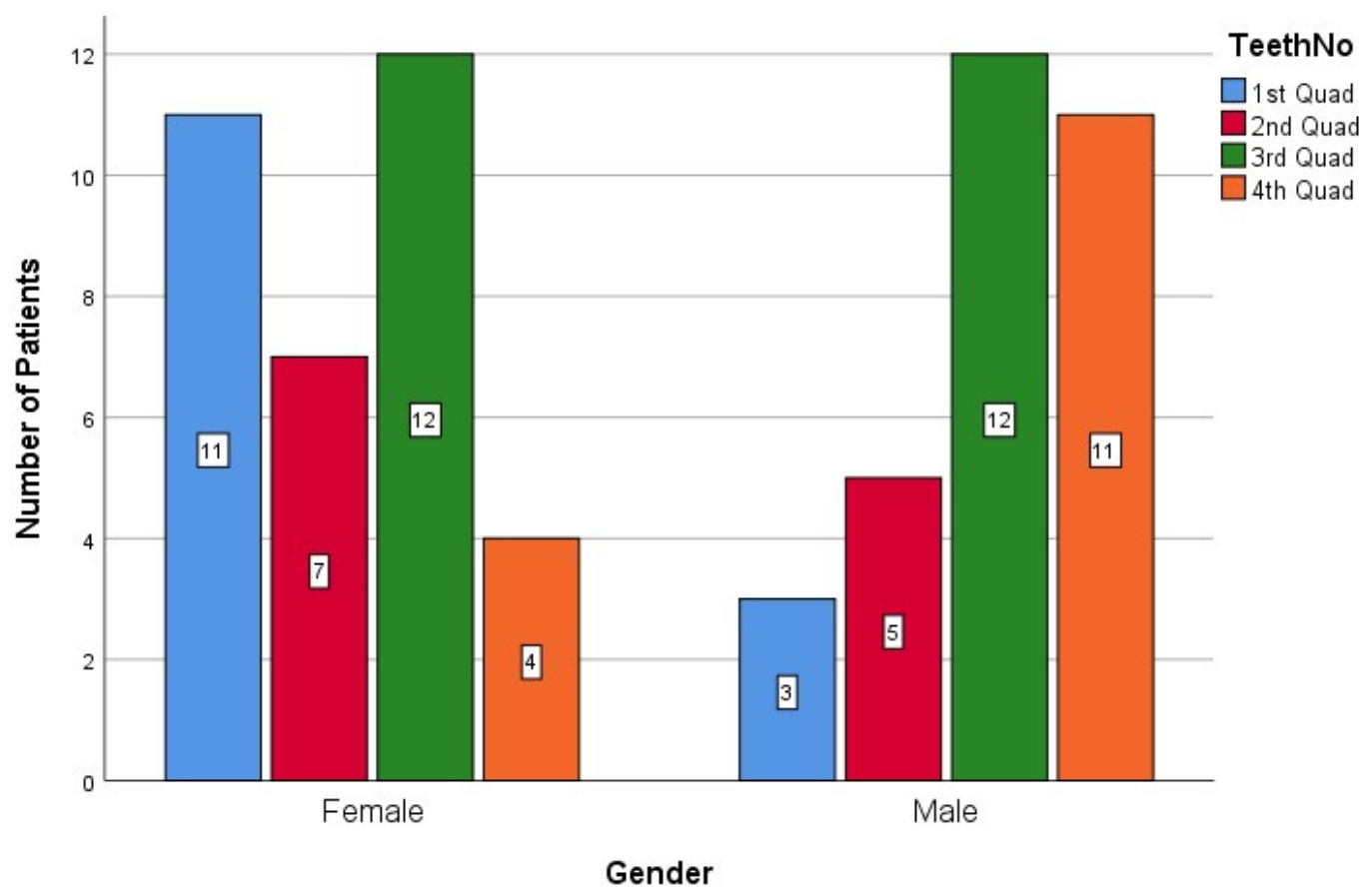

Figure 3: Bar graph showing the association between the gender of the patients and teeth no. of the patients who reported with instrument separation. The $X$ axis denotes the gender of the patient and $Y$ axis represents the teeth no. of the patient. The blue colour denotes the 1 st quadrant with instrument separation, red colour denotes the 2 nd quadrant with instrument separation, green colour denotes the 3rd quadrant with instrument separation and orange colour denotes the 4th quadrant with instrument separation. It was found that the instrument separation or breakage in 3rd quadrant was more common in both male and female patients than in any other quadrant. Chi square statistical test was done and the association was found to be not significant with $p$ value .208 ( $P$ value - $>0.005$, statistically not significant).

\section{CONCLUSION}

In this study, the instrument separation alone by the undergraduate and postgraduate was reported to be $23.4 \%$. On the basis of the results of the present study, NiTi rotary instruments show a slightly more frequent tendency to fracture during root canal mechanical instrumentation than stainless steel hand instruments. However, under the working conditions of our clinic, we believe that the fracture frequency of NiTi rotary and stainless steel hand instruments remains at a low level. This procedural mishap can be effectively minimized. To overcome the accidents, the students or practitioners should be acknowledged about the canal preparation and modification before using the files, this will reduce the chances of file breakage or instrument separation.

\section{REFERENCES}

[1] Grossman LI. Guidelines for the prevention of fracture of root canal instruments. Oral Surg Oral Med Oral Pathol [Internet]. 1969 Nov; 28(5): 746-52. Available from: http://dx.doi.org/10.1016/00304220(69)90423-x

[2] Crump MC, Natkin E. Relationship of broken root canal instruments to endodontic case prognosis: a clinical investigation. J Am Dent 
Assoc [Internet]. 1970 Jun; 80(6): 1341-7. Available from: http://dx.doi.org/10.14219/jada.arch ive. 1970.0259

[3] Pruett JP, Clement DJ, Carnes DL Jr. Cyclic fatigue testing of nickeltitanium endodontic instruments. J Endod [Internet]. 1997 Feb; 23(2): 77-85. Available from: http://dx.doi.org/10.1016/S00992399(97)80250-6

[4] Serene, P T. Nickel-Titanium Instruments : Application In Endodontics. Application In Endodontics [Internet]. 1995 [Cited 2020 Jun 15]; 1-5. Available From: https://ci.nii.ac.jp/naid/1000931161 8/

[5] Kazemi RB, Stenman E, Spångberg LSW. A comparison of stainless steel and nickel-titanium H-type instruments of identical design: Torsional and bending tests. Oral Surgery, Oral Medicine, Oral Pathology, Oral Radiology, and Endodontology [Internet]. 2000 Oct 1; 90(4): 500-6. Available from: http://www.sciencedirect.com/scien ce/article/pii/S107921040080596X

[6] Gluskin AH, Ruddle CJ, Zinman EJ. Thermal injury through intraradicular heat transfer using ultrasonic devices: Precautions and practical preventive strategies. The
Journal of the American Dental Association [Internet]. 2005 Sep 1; 136(9): 1286-93. Available from: http://www.sciencedirect.com/scien ce/article/pii/S0002817714631135

[7] Teja KV, Ramesh S, Priya V. Regulation of matrix metalloproteinase-3 gene expression in inflammation: A molecular study. J Conserv Dent [Internet]. 2018 Nov; 21(6): 592-6. Available from: http://dx.doi.org/10.4103/JCD.JCD_ $154 \_18$

[8] Rajendran R, Kunjusankaran RN, Sandhya R, Anilkumar A, Santhosh R, Patil SR. Comparative Evaluation of Remineralizing Potential of a Paste Containing Bioactive Glass and a Topical Cream Containing Casein Phosphopeptide-Amorphous Calcium Phosphate: An in Vitro Study. Pesqui Bras Odontopediatria Clin Integr [Internet]. 2019;19. Available from: http://www.scielo.br/scielo.php?pid $=\mathrm{S} 1983$ 46322019000100364\&script=sci_ar ttext

[9] Rajakeerthi R, Ms N. Natural Product as the Storage medium for an avulsed tooth--A Systematic Review. Cumhuriyet Dental Journal [Internet]. 2019; 22(2): 249-56. 
Available

from:

https://dergipark.org.tr/en/pub/cumu

dj/issue/45584/525182

[10] Siddique R, Sureshbabu NM, Somasundaram J, Jacob B, Selvam D. Qualitative and quantitative analysis of precipitate formation following interaction of chlorhexidine with sodium hypochlorite, neem, and tulsi. J Conserv Dent [Internet]. 2019 Jan; 22(1): 40-7. Available from: http://dx.doi.org/10.4103/JCD.JC

D_284_18

[11] Ramanathan S, Solete P. Conebeam Computed Tomography Evaluation of Root Canal Preparation using Various Rotary Instruments: An in vitro Study. J Contemp Dent Pract [Internet]. 2015 Nov 1;16(11):869-72. Available from: http://dx.doi.org/10.5005/jpjournals-10024-1773

[12] Ramamoorthi S, Nivedhitha MS, Divyanand MJ. Comparative evaluation of postoperative pain after using endodontic needle and EndoActivator during root canal irrigation: A randomised controlled trial. Aust Endod J [Internet]. 2015 Aug; 41(2): 78 87. Available from: http://dx.doi.org/10.1111/aej.1207
6

[13] Manohar MP, Sharma S. A survey of the knowledge, attitude, and awareness about the principal choice of intracanal medicaments among the general dental practitioners and nonendodontic specialists. Indian J Dent Res [Internet]. 2018 Nov 1 [cited 2020 Jun 3]; 29(6): 716. Available from: http://www.ijdr.in/article.asp?issn $=0970$ -

9290; year $=2018$; volume $=29$; issue $=6 ;$ spage $=716 ;$ epage $=720 ;$ aulast $=$ Manohar

[14] Ravinthar K, Others. Recent Advancements in Laminates and Veneers in Dentistry. Research Journal of Pharmacy and Technology [Internet]. 2018; 11(2): 785-7. Available from: http://www.indianjournals.com/ijo r.aspx?target $=$ ijor:rjpt\&volume $=1$ $1 \&$ issue $=2 \&$ article $=070$

[15] Jose J, P. A, Subbaiyan H. Different Treatment Modalities followed by Dental Practitioners for Ellis Class 2 Fracture - A Questionnaire-based Survey [Internet]. Vol. 14, The Open Dentistry Journal. 2020. p. 59-65. Available from: http://dx.doi.org/10.2174/1874210 602014010059 
[16] Janani K, Palanivelu A, Sandhya R. Diagnostic accuracy of dental pulse oximeter with customized sensor holder, thermal test and electric pulp test for the evaluation of pulp vitality: an in vivo study. Brazilian Dental Science [Internet]. 2020; 23(1): 8 . Available from: https://200.145.25.12/index.php/co b/article/view/1805

[17] [17] Noor SSSE, S Syed Shihaab, Pradeep. Chlorhexidine: Its properties and effects [Internet]. Vol. 9, Research Journal of Pharmacy and Technology. 2016. p. 1755. Available from: http://dx.doi.org/10.5958/0974360x.2016.00353.x

[18] Teja KV, Ramesh S. Shape optimal and clean more. Saudi Endodontic Journal [Internet]. 2019; Available from: http://www.saudiendodj.com/articl e.asp?issn=16585984; year $=2019$; volume $=9 ;$ issue $=$ $3 ;$ spage $=235 ;$ epage $=236$; aulast $=\mathrm{Te}$ ja

[19] Kumar D, Antony S. Calcified Canal and Negotiation-A Review. Research Journal of Pharmacy and Technology [Internet]. 2018; 11(8): 3727-30. Available from: http://www.indianjournals.com/ijo r.aspx?target $=$ ijor:rjpt $\&$ volume $=1$

$1 \&$ issue $=8 \&$ article $=088$

[20] Nandakumar M, Nasim I. Comparative evaluation of grape seed and cranberry extracts in preventing enamel erosion: An optical emission spectrometric analysis. J Conserv Dent [Internet]. 2018 Sep; 21(5): 51620. Available from: http://dx.doi.org/10.4103/JCD.JC D_110_18

[21] Hussainy SN, Nasim I, Thomas T, Ranjan M. Clinical performance of resin-modified glass ionomer cement, flowable composite, and polyacid-modified resin composite in noncarious cervical lesions: One-year follow-up. J Conserv Dent [Internet]. 2018 Sep; 21(5): 510-5. Available from: http://dx.doi.org/10.4103/JCD.JC D_51_18

[22] Gambarini G. Cyclic Fatigue of Nickel-Titanium Rotary Instruments after Clinical Use with Low-and High-Torque Endodontic Motors. J Endod [Internet]. 2001 Dec 1; 27(12): 772-4. Available from:

http://www.sciencedirect.com/scie nce/article/pii/S009923990561039 4

[23] Frank RJ. Endodontic mishaps: 
their detection, correction, and prevention. Endodontics 5th ed Hamilton: BC Decker Inc. 2002; 769-89.

[24] Hülsmann M, Schinkel I. Influence of several factors on the success or failure of removal of fractured instruments from the root canal. Endod Dent Traumatol [Internet]. 1999 Dec; 15(6): 2528. Available from: http://dx.doi.org/10.1111/j.16009657.1999.tb00783.x

[25] Madarati AA, Qualtrough AJ, Watts DC. Factors Affecting Temperature Rise on the External Root Surface During Ultrasonic Retrieval of Intracanal Separated Files. J Endod [Internet]. 2008 Sep 1; 34(9): 1089-92. Available from:

http://www.sciencedirect.com/scie nce/article/pii/S009923990800492 5

[26] Ward JR, Parashos P, Messer HH. Evaluation of an Ultrasonic Technique to Remove Fractured Rotary Nickel-Titanium Endodontic Instruments from Root Canals: An Experimental Study. J Endod [Internet]. 2003 Nov 1; 29(11): 756-63. Available from: http://www.sciencedirect.com/scie nce/article/pii/S009923990560369
$\mathrm{X}$

[27] Souter NJ, Messer HH. Complications Associated with Fractured File Removal Using an Ultrasonic Technique. J Endod [Internet]. 2005 Jun 1; 31(6): 4502.

http://www.sciencedirect.com/scie nce/article/pii/S009923990560850 3

[28] Madarati AA, Watts DC, Qualtrough AJE. Opinions and attitudes of endodontists and general dental practitioners in the UK towards the intra-canal fracture of endodontic instruments. Part 2. Int Endod J [Internet]. 2008; 41(12): 1079-87. Available from:

https://onlinelibrary.wiley.com/doi /abs/10.1111/j.1365-

2591.2008.01473.x

[29] Song M, Shin S-J, Kim E. Outcomes of Endodontic Microresurgery: A Prospective Clinical Study. J Endod [Internet]. 2011 Mar 1; 37(3): 316-20. Available from:

http://www.sciencedirect.com/scie nce/article/pii/S009923991000965 9

[30] Tang Y, Li X, Yin S. Outcomes of MTA as root-end filling in endodontic surgery: a systematic 
review. Quintessence Int [Internet]. 2010;41(7). Available from:

http://search.ebscohost.com/login. aspx $?$ direct $=$ true $\&$ profile $=$ ehost $\& s$ cope $=$ site \&authtype $=$ crawler\&jrnl $=00336572 \& A N=52247829 \& \mathrm{~h}=\mathrm{D}$ pdUwXuom4UZRIVp19U\%2BJbg \%2FgjvBPYvMQw0fh\%2B6\%2Ft qlfnAYceGu1w7K8YTwWxzREI oi86FuGoj0JNCRKUg2RhA\%3D $\% 3 \mathrm{D} \& \mathrm{crl}=\mathrm{c}$

[31] Madarati AA, Qualtrough AJE, Watts DC. Vertical fracture resistance of roots after ultrasonic removal of fractured instruments. Int Endod J [Internet]. 2010 May;43(5):424-9. Available from: http://doi.wiley.com/10.1111/j.136 5-2591.2010.01698.x

[32] Hegde R, Sumanth S, Padhye A. Microscope-enhanced periodontal therapy: a review and report of four cases. J Contemp Dent Pract [Internet] [Internet]. 2009; Available from: https://pdfs.semanticscholar.org/09 20/0e04b971c41b749d97fb8e25c6 c5edcfd82d.pdf

[33] Kang M, In Jung H, Song M, Kim SY, Kim H-C, Kim E. Outcome of nonsurgical retreatment and endodontic microsurgery: a metaanalysis. Clin Oral Investig
[Internet]. 2015 Apr 1; 19(3): 56982.

Available from: https://doi.org/10.1007/s00784015-1398-3 